\title{
A Lean Six Sigma approach to the improvement of the selenium analysis method
}

\author{
Authors: \\ Bronwyn C. Cloete ${ }^{1}$ \\ André Bester ${ }^{2}$ \\ Affiliations: \\ ${ }^{1}$ Western Cape Provincial \\ Veterinary Laboratory, \\ Histology Section, \\ South Africa \\ ${ }^{2}$ Department of Industrial \\ and Systems Engineering, \\ Cape Peninsula University of \\ Technology, Bellville Campus, \\ South Africa

\section{Correspondence to:} \\ Bronwyn Cloete \\ Email: \\ bronwyncloete@gmail.com \\ Postal address: \\ Private Bag 5020, \\ Stellenbosch 7599, \\ South Africa \\ Dates: \\ Received: 27 Jan. 2012 \\ Accepted: 12 Aug. 2012 \\ Published: 02 Nov. 2012 \\ How to cite this article: \\ Cloete, B.C. \& Bester, \\ A., 2012, 'A Lean Six \\ Sigma approach to the \\ improvement of the \\ selenium analysis method', \\ Onderstepoort Journal of \\ Veterinary Research 79(1), \\ Art. \#407, 13 pages. http:// \\ dx.doi.org/10.4102/ojvr. \\ v79i1.407
}

C 2012. The Authors. Licensee: AOSIS OpenJournals. This work is licensed under the Creative Commons Attribution License.
Reliable results represent the pinnacle assessment of quality of an analytical laboratory, and therefore variability is considered to be a critical quality problem associated with the selenium analysis method executed at Western Cape Provincial Veterinary Laboratory (WCPVL). The elimination and control of variability is undoubtedly of significant importance because of the narrow margin of safety between toxic and deficient doses of the trace element for good animal health. A quality methodology known as Lean Six Sigma was believed to present the most feasible solution for overcoming the adverse effect of variation, through steps towards analytical process improvement. Lean Six Sigma represents a form of scientific method type, which is empirical, inductive and deductive, and systematic, which relies on data, and is fact-based. The Lean Six Sigma methodology comprises five macro-phases, namely Define, Measure, Analyse, Improve and Control (DMAIC). Both qualitative and quantitative laboratory data were collected in terms of these phases. Qualitative data were collected by using quality-tools, namely an Ishikawa diagram, a Pareto chart, Kaizen analysis and a Failure Mode Effect analysis tool. Quantitative laboratory data, based on the analytical chemistry test method, were collected through a controlled experiment. The controlled experiment entailed 13 replicated runs of the selenium test method, whereby 11 samples were repetitively analysed, whilst Certified Reference Material (CRM) was also included in 6 of the runs. Laboratory results obtained from the controlled experiment was analysed by using statistical methods, commonly associated with quality validation of chemistry procedures. Analysis of both sets of data yielded an improved selenium analysis method, believed to provide greater reliability of results, in addition to a greatly reduced cycle time and superior control features. Lean Six Sigma may therefore be regarded as a valuable tool in any laboratory, and represents both a management discipline, and a standardised approach to problem solving and process optimisation.

\section{Introduction}

\section{Setting}

The function of the Biochemistry laboratory at Western Cape Provincial Veterinary Laboratory (WCPVL) is to render accurate and precise analytical data to pathologists so that correct diagnoses can be made. Focus on quality in analytical testing laboratories, including the WCPVL Biochemistry laboratory, has enjoyed increasing importance as SANS 17025 (2005) became more prominent in laboratories country-wide. This quality evolution is similar to that experienced by manufacturing and other service sectors of the world economy. Quality is defined as a spectrum of activities and processes that shape the characteristics of a product or service. Thus, an undisputed benefit to a laboratory that desires reliability as a characteristic of their results output will follow from adopting a quality approach, which can address the root causes of sources of variability in laboratory processes (Nevalainen 1999). Lean Six Sigma is one such approach.

Lean Six Sigma is a combination of certain tools and techniques that provides laboratory quality practitioners with a means to improve processes and reduce cycle times. This approach incorporates the use of Six Sigma methodology, which inherently focuses on gathering data, analysing the collected data, and thereafter improving the process yield, as well as the Lean methodology which identifies key areas of variation (Khalil, Khan \& Mahmood 2006).

\section{Key focus}

From a quality-engineering perspective, the selenium analysis test method may be considered to be analytical laboratory service process. According to Cawley (2000), Statistical Quality Control (SQC) techniques are being employed with significant success to improve analytical confidence and the capability of laboratory processes, and they benefit continuous process improvement efforts. Furthermore, laboratory managers need to understand that there is an underlying process in generating analytical results, the process can be managed, and the process must evolve through a programme of continuous improvement. 
An approach to improve the Selenium Analysis Process at WCPVL led to the statement of the following research hypothesis, ' $\mathrm{H}_{0}$ : variation in process, time and control procedures has a direct impact on the disparity in selenium testing results'. In this hypothesis, variation in process, time and control serve as the dependent variable, whilst disparity in selenium testing results serves as the independent variable.

\section{Background}

Selenium is one of the rarest chemical elements and is considered an essential trace element (Tarin 2006). Selenium analysis processes have, however, traditionally posed several challenges because of the complex chemical properties of selenium. The main difficulty with the selenium analysis process is sample mineralisation. Organic forms of selenium (dimethylselenide and dimethyldiselenide) volatilise from a sample at a temperature exceeding $70^{\circ} \mathrm{C}$; therefore, a loss of selenium yield can occur in an open digestion system and could, as a result, return inaccurate results (Kurkova,Skrypnik \& Zaeckiene 2008). Furthermore, for selenium analysis to occur, total decomposition of organic material is essential, because selenium values cannot be detected analytically and measured without the release of selenium from the prevalent protein form (selenomethionine and selecysteine) found in biological samples when digested in an acid matrix. As a result, an adequate and total digestion process must be followed. In addition, certain selenium detection techniques such as fluorimetry, Hydride Generation Atomic Absorption Spectrophotometry (HG-AAS), and Hydride Generation Inductively Coupled Plasma Mass Spectrometry (HGICP-MS), require chelate or hydride formation, which are convenient only in total digestion (Tarin 2006).

\section{Objectives}

The primary objective of this paper was 'quality improvement on the Selenium Analysis Process by following a Lean Six Sigma model'. The Define, Measure, Analyse, Improve and Control (DMAIC) phases of Six Sigma are based on Deming's Plan-Do-Check-Act (PDCA) cycle. According to Moen and Norman (2011), the PDCA cycle is firmly rooted in the traditional phases of the scientific method. Secondary research objectives were 'to determine whether a modified microwave sample digestion procedure was capable of reducing risks associated with the digestion procedure'. In addition, the objective was 'to optimise the yield of the selenium and ultimately to translate it into an improvement in quality in terms of reliability of results'.

\section{Contribution to field}

The approach followed by the researcher is regarded as a model for improvement, which is as a rule employed by any biochemistry or analytical chemistry laboratory. This approach incorporates standard chemistry laboratory validation techniques, and serves as an example of how a quality-methodology can be used to assure and improve analytical quality.

\section{Literature review}

In support of an analytical test method being described as a service process, the American Association for Clinical Chemistry (AACC) (2011) describes an analytical method as '... a science professionally conducted with rigorous statistical analysis, quality controls, and extensive oversight', whilst Wang (2008) deliberates that the quality improvement process starts with a diagnostic journey of the process, where problems as well as symptoms are identified. Thereafter a hypothesis is formulated and tested, and root causes are identified. Finally, remedial action is taken and the process is then continuously monitored.

Scott (2007) contends that a plethora of process improvement approaches exist and is of the opinion that 'continuous process improvement methods include define, measure, analyse, improve and control, plan-do-study-act, Six Sigma and total quality management'. (Foster 2007), however, points out that there are seven basic tools, known also as the seven basic tools, typically used for process improvement. Whilst the basic tools are commonly used in a logical order, they can, however, be used in any order. These quality-tools are Ishikawa diagrams (Root Cause and Effect diagrams), Pareto charts, Process Maps (Flowcharts), Check sheets, Histograms, Scatter plots and Control charts. Berte's (2007) opinion is that a means of improving laboratory test processes at bench level are accomplished by quality improvement programmes. Programmes include the use of statistical quality-tools, which provide a visual means to understand quality-control data, so that timely action can be taken when method problems are detected.

The merger between Six Sigma and Lean results in a powerful Lean Six Sigma tool, because the strengths from each individual method are secured (Table 1).

Statistical Process Control (SPC) is defined as 'the application of statistical methods to the measurement and analysis of variation in a process' (Gryna, Chua \& DeFeo 2007). Woodall (2000:341) describes SPC as 'a sub-area of Statistical Quality Control (SQC), consisting of methods for understanding,

TABLE 1: Comparison between Lean and Six Sigma.

\begin{tabular}{|c|c|c|}
\hline $\begin{array}{l}\text { Methodology } \\
\text { characteristic }\end{array}$ & Lean & Six Sigma \\
\hline Focus and objective & $\begin{array}{l}\text { Waste reduction and } \\
\text { flow improvement }\end{array}$ & $\begin{array}{l}\text { Process improvement } \\
\text { and variation reduction }\end{array}$ \\
\hline Applicability & $\begin{array}{l}\text { Predominantly } \\
\text { manufacturing and } \\
\text { supply chain } \\
\text { management }\end{array}$ & All types of processes \\
\hline Process approach & Speedy and focussed & Discipline of steps \\
\hline Execution focus & $\begin{array}{l}\text { Predominantly team } \\
\text { focus }\end{array}$ & Customer focus \\
\hline Data driven style & $\begin{array}{l}\text { Quantitative and } \\
\text { qualitative }\end{array}$ & $\begin{array}{l}\text { Predominantly } \\
\text { quantitative }\end{array}$ \\
\hline Cost of implementation & Relatively low & Relatively higher \\
\hline Solution approach & Process orientated & Statistical orientated \\
\hline
\end{tabular}

Source: Khalil, M., Khan, M. \& Mahmood, T., 2006, 'Lean Six Sigma - A tool to improve productivity, quality and efficiency in manufacturing and industrial sector', paper presented at the Official Conference of the International Association for Management Technology, P. R. China, Beijing, 22-26th May 
monitoring and improving process performance over time'. Woodall (2000) and Hare (2001) shared the opinion that understanding process variation is key to SPC. These authors maintain that there are at least two basic kinds of variation, which affect a process, namely common cause variation and special cause variation. Park and Anthony (2008:5) state that '... variation is the main enemy of quality', whilst Jiang, Murphy and Tsui (2006) believes that the objective of statistical process control is to identify and remove special cause variation as quickly as possible.

Wu, Pearn and Kotz (2009:339) consider process capability studies to be 'an important and well-defined tool in applications of statistical process control (SPC) to continuous improvement of quality and productivity'. The authors state that the relationship between specification limits and tolerance limits of a process, and the actual process performance, may be quantified by using suitable process capability indices. Foster (2007) maintains that a process can be considered capable if individual results consistently meet specification; however, it is important to note that a process is considered stable only if special cause variation is not present in the process. As a result process capability studies are arguably seen to be the most fundamental toolset available for quality-improvement purposes on a process, as summarised by Marquis (2011), stating:

The clinical chemist must check whether uncertainty of all his analytical methods is compatible with the tolerance required by medical needs. It is the aim of the capability index. If the uncertainty interval of a method is greater than the tolerance interval, the analytical method must be discarded or improved. (n.p.)

For process capability studies to be conducted on an analytical chemistry process, it is important to determine and obtain the appropriate result measures (also known as R-criteria) from the process being studied. R-criteria represent the true process results, and as a result $\mathrm{R}$-criteria are data, which are collected of overall process performance (Process Management International 2009). R-criteria closely track how well customer requirements are being met. This is executed by the determination of accuracy and precision of the analytical chemistry process. A controlled experiment is therefore designed and conducted in order to obtain quantitative result measures (R-criteria) or process results. A further measure known as process measures (P-criteria), represents process characteristics that are expected to affect the 'process results' (Dahlgaard, Kristensen \& Gopal 2002). From a Lean Six Sigma perspective, R-criteria are considered to be quality-control points, whilst P-criteria are quality checkpoints. P-criteria are data measured or obtained from practical process steps. The state of the process may therefore be measured by a quality checkpoint or P-criteria.

Failure Modes and Effects Analysis (FMEA) is described as a reliability analysis tool, or a methodology to make process designs more reliable. Failure Modes and Effects Analysis is the systematic consideration of each component in a system, and involves the identification, analysis and documentation of the possible failure modes within a system, as well as the effects of each potential failure in the system (Foster 2007). Some of the benefits of FMEA are listed below:

- improvement of safety, quality and reliability

- improvement of a company's imageand its competitiveness

- increased satisfaction from a user standpoint

- reduction in development cost

- records of actions taken to reduce risk.

Van Leeuwen et al. (2009) argue that, as a quality-tool, FMEA has high improvement potential when applied to clinical laboratory processes. Failure Modes and Effects Analysis is a highly structured systematic assessment, which generates a comprehensive review to safeguard against system performance problems. Failure Modes and Effects Analysis is able to assure process and quality features, which are designed into the modified process (FMEA Information Centre 2011).

Blumberg, Cooper and Schindler (2011:13) are of the opinion that 'good research follows the structure of the scientific method', from which the analogy can be drawn that the structured Lean Six Sigma approach, which is inherently scientific and comprises distinct phases, provides a suitable platform to conduct research in a scientific laboratory environment. Allen (2006) regards Six Sigma as:

... an organised and systematic problem-solving method for strategic system improvement that relies on statistical methods and the scientific method to make dramatic reductions in customer defined defect rates and/or improvements in key outputs variables. (p. 8)

Following the Lean Six Sigma process map makes it possible for value to be identified within a process. Process efficiency of both current state and future state can be determined. This drives improvement actions and tasks to a future state process. The Lean Six Sigma process map also addresses process waste through Kaizen analysis, and identifies muda (non-value activities), muri (volatile work-in-progress) and mura (un-standardised working practice during sample processing) present in a process. Process standardisation is regarded as a form of process improvement (American Society for Quality 2011; Anvari, Ismail \& Hojjati 2011; Byrne, Lubowe \& Blitz 2008; Hubbard 2010). As a result, the analogy can be drawn that Lean Six Sigma provides a dominant and innovative tool, developed on the basis provided by the scientific method and capable of process improvement and concurrent reduction of process variation on an analytical chemistry process.

Many techniques have been developed for selenium analysis, including fluorimetry, Electrothermal Atomic Absorption (ET-AAS), HG-AAS, Neutron Activation Analysis (NAA), and different mass spectrophotometry methods. These methods include Gas Chromatography Spectrophotometry (GC-MS), thermal ionisation mass spectrophotometry and, more recently, Inductively Coupled Plasma Mass Spectrophometry (ICP-MS). All of these methods (except NAA and ET-AAS for some sample types) require a prior 
sample digestion to decompose organic matter before detection can occur (Ducros et al. 1994).

The technique of choice depends on the sample matrix, sample concentration and the type of information required (e.g. isotope or selenium species). The selenium analysis process thus predominantly involves two main sequential steps, namely, digestion of samples and thereafter, detection of the selenium in samples. Any changes to improve any one part of the process cannot be made without consideration for the other, because of the complex chemical nature of the element selenium (Tarin 2006).

As a result of the very narrow margin between deficient and toxic levels of selenium in healthy organisms, it is crucial that any laboratory rendering the service of selenium analysis takes steps to ensure the accuracy of their diagnostic service. Thus, during the development of an improved selenium analysis technique, it is important to take into consideration the specific process requirements, namely, total decomposition of organic material (chemically releasing selenium from the selenomethionine and selenocysteine form in biological samples), and the preservation of selenium yield (as selenium volatilises from samples at a temperature exceeding $70{ }^{\circ} \mathrm{C}$ ).

Sample digestion in a closed system, such as a microwave digestion system, was believed to be capable of overcoming this challenge. For fluorometric detection of selenium, however, the oxidation state of selenium, as well as interference from nitrate ions and analyte $\mathrm{pH}$ which occurs as a result of microwave digestion, severely inhibits accurate selenium detection (Kurkova et al. 2008). Microwave digestion, as a means to overcome challenges associated with open heat-block digestion, is therefore only possible with an alternative detection method such as hydride generation or HG-AAS.

\section{Materials and methods Materials}

This research was focussed on the improvement of an analytical method, (referred to as an analytical process, in quality terms), and therefore the primary subject of research is considered to be the trace element, namely selenium, being analysed in the process under scrutiny.

\section{Setting}

The focus of this research vested with investigating potential improvements of the digestion procedure as a means to mitigate quality concerns pertaining to the selenium analysis process employed by WCPVL. Research has highlighted that microwave digestion was a suitable alternative to openheat-block sample digestion, as microwave digestion would lead to augmented digestion, in terms of selenium yield and recovery. Furthermore, under microwave conditions, higher digestion temperatures can be reached, increasing the rate of digestion. As a result, it reduces digestion time from hours to minutes. Oxidising conditions are maintained stably throughout the digestion procedure, and complete digestion can be achieved with one acid, eliminating the need to mix acids and consequently reducing the risk of contamination (Tarin 2006).

Laboratory trials conducted, returned that successful modification of the digestion method could not be accomplished without the additional modification of the detection technique. It was found that fluorometric detection of selenium was impossible in samples which had not undergone the required chemical redox reaction. The openblock digestion process enabled chemical redox reaction but microwave digestion did not return the same results; therefore, further processing of microwave digested samples was required. Furthermore, fluorometric selenium detection was also inhibited by a low sample $\mathrm{pH}$ and excess nitric acid, which remained in samples after microwave digestion. As a result, a Standard Operating Procedure (SOP), which employed the use of both microwave digestion and HG-AAS detection, was required.

\section{Procedure}

The research method followed the Lean Six Sigma five phases, commonly known as DMAIC, representing the acronym for 'Define', 'Measure', 'Analyse', 'Improve' and 'Control'; therefore, the following research design was followed:

- define(d) the problem or selenium analysis improvement opportunity phase

- measure(d) the process criteria phase

- analyse(d) the result criteria phase

- improve(d) and optimise(d) the selenium analysis process phase

- control(led) the selenium analysis process.

Systematic data analysis thus took place in the order which is specified by the Lean Six Sigma process map. During the Define phase of Lean Six Sigma, the purpose of the process was established. Furthermore, the extent to which the process met the requirements (customer) was defined during this phase, as well as how the process was monitored. The influence and extent of variation present in the process was also determined during this phase. Research design operational implications of the Define phase involved:

- the identification of process steps from a process map

- evaluation of a root cause analysis diagram

- assignable causes of process problems were listed

- Pareto analysis was conducted to highlight the most critical problem(s) in the process

- a detailed current state value map was drafted

- the improvement opportunity to be addressed was selected.

During the Measure phase both types of measures which were required, namely process measures (P-criteria) and result measures (R-criteria), were collected. Measures were analysed to provide an assessment of the current performance of the process, and to obtain information of changes to the process. Signals of potential problems in 
the process were also identified through the evaluation of P-criteria. A controlled experiment was conducted to obtain R-criteria. The controlled experiment involved the processing of 10 non-probability, purposively selected liver samples from an archived population of all the previously processed samples processed by the laboratory. In addition to these, an in-house control sample was added to the sample group. All samples in this sample group were processed with the current state selenium analysis method, and replicated 13 times. Furthermore, during the six trial runs, an international Certified Reference Material (CRM) sample was included to determine the deviation from trueness from the true accurate value (concentration). The confidence intervals of the CRM, and the quality of the standard curve fit, served as a guideline for the determination of analytical accuracy.

A blank sample, as well as a set of five standard calibration samples, was included with each process trial run. The experiment was designed so that measurement data obtained from the calibration standards served the purpose of assessing the analytical precision of the process.

During the Analyse phase of the Lean Six Sigma process, the primary tools used to analyse data are inherently Six Sigma tools, namely statistical tools such as SPC, including Analysis of Variation (ANOVA) and confidence intervals, as well as regression analysis. This phase is referred to as 'Listening to the voice of the process' (Process Management International 2009).

The analysis and interpretation of R-criteria was thus conducted in the following order:

- Total Regression uncertainty analysis. During the Total Regression uncertainty analysis, Quantitative method characteristics of the standard calibration curve of the current state fluorimetry selenium analysis process were identified through the analysis of raw data R-criteria.

- Certified Reference Material analysis. The accuracy and precision of CRM measurements were analysed also with respect to average linearity and characteristics established for total regression analysis of the average process standard calibration curve.

- Precision, Analytical Bias and HorRat (Horwitz ratio) analysis. The precision or closeness with which results of the replicated analyses of a sample agree, the bias or consistent deviation of analytical results from true value', as well as the HorRat ratio or method's performance with regard to precision, of the current state selenium analysis process were determined.

- Analysis of individual standard curves of process runs. Data collected from each individual process run, were analysed with statistical tools by plotting the data into scatter plots and histograms and with ANOVA hypothesis testing.

- Systematic error analysis. A Cochran variant of the $t$-hypothesis test was conducted as a means to evaluate systematic error, related to accuracy in the process. This determined whether systematic error present could be considered as statistically significant by assessing whether or not the average CRM measurement obtained from process runs was different from the value stated by the reputed CRM supplier.

- Process capability analysis. This involved statistical analysis that determined whether the analytical test process was capable of performing within the tolerance level as specified by the internationally certified CRM supplier. Divergent from process capability studies conducted by manufacturing quality practitioners, in the specialist area of clinical chemistry, an important factor known as total analytical uncertainty, has to be taken into account. As a result, based on literature review, process capability indices were adapted accordingly to make provision for the important laboratory consideration.

During the Improve phase, focus shifted to the evaluation of P-criteria once again. An identifiable characteristic of this phase involved improvement solutions being developed to address root causes of problems identified. As a result, alternative remedies were evaluated to secure a quality improvement on the process. A quality-tool known as Kaizen analysis, taken from the Lean bouquet of quality-tools, was the primary tool used in this phase. The Improve phase provided improvement direction, and led to the redesign of the selenium analysis process.

The Optimise process sub-phase as employed to secure the best possible process improvement solution and this subphase relied on R-criteria data, in addition to P-criteria. The P-criteria were used to develop improvement remedies as part of the research conducted to improve the selenium analysis process, and R-criteria obtained from the improved designs were used to evaluate the effectiveness of the solutions developed. The following R-criteria analysis and interpretation formed part of the Optimise sub-phase:

- Process variance analysis. Statistical analysis determined whether the variance observed in the two analytical processes differed with statistical significance from each other. An independent $t$-test was used to compare the variance around the means of the two laboratory methods.

- Non-parametric difference in mean analysis. This type of analysis was performed to determine the extent of the quality improvement, as a result of the Lean Six Sigma process modification, whereby the R-criteria process means of the two analytical processes were statistically compared. The variable of interest in this type of analysis was the difference between the values of replicate observations, rather than the values of the observations themselves.

The Control phase of Lean Six Sigma utilised a feedback loop, whereby the standard performance of the improvement process was compared to actual performance, and action was taken to maintain the gains of improvements secured. In this phase, the quality-tool, FMEA, was used as the final step in the approach to the improvement of the selenium analysis process of the Western Cape Provincial Veterinary Laboratory. The steps of this phase were, (1) design 


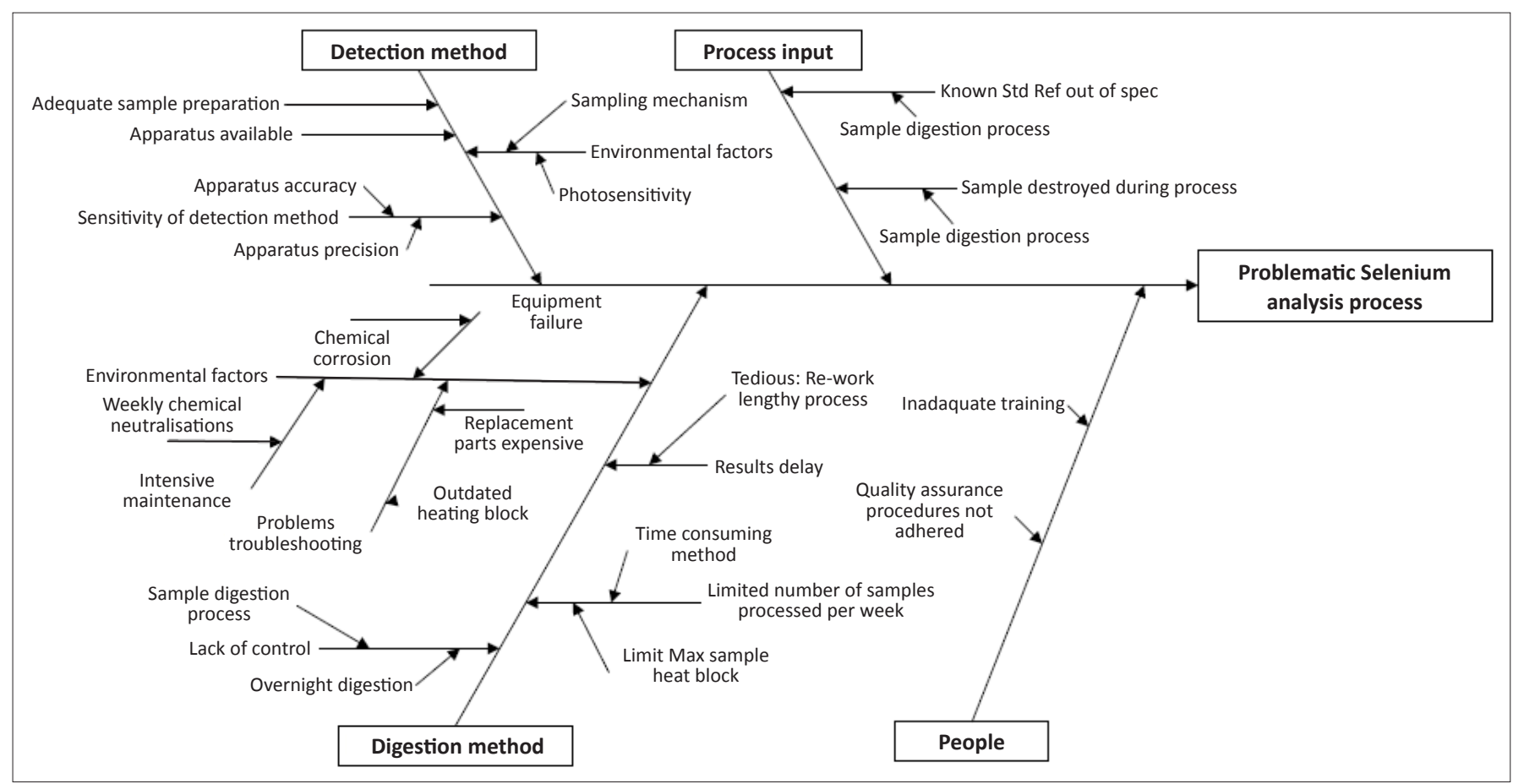

FIGURE 1: Ishikawa root cause analysis diagram.

controls and document the improved process, (2) validate the measurement system, (3) determine the final process capability and (4) implement and monitor controls.

The DMAIC method emphasises data analysis and factbased decision making. The essence of the DMAIC method is to reduce variation in a process in order to achieve high conformance to customer requirements. As a result, the Lean Six Sigma methodology provides an exceptional research structure and design, as used for the purpose of improving an analytical process.

\section{Ethical considerations}

No human or animal participants were used during research conducted for this paper, and as a result, no ethical considerations were applicable.

\section{Results}

The Lean Six Sigma approach to the quality improvement of the selenium analysis process was regarded as a technique, which provided quality practitioners with a mechanism to reduce process time, whilst minimising variation and reducing process waste simultaneously. Ultimate process improvement was initially directed during the initial stages as a result of analogies being drawn from the literature review, and in the latter stages, by analogies drawn from the analysis and interpretation of data obtained through the DMAIC phases of Lean Six Sigma.

A schematic of results obtained during the Define phase is seen in the form of an Ishikawa chart (Figure 1), a Pareto chart (Figure 2, Table 2 and 3) and a Current State Value Stream (Figure 3 and Table 4). The phase entailed a detailed evaluation of the current state selenium analysis process

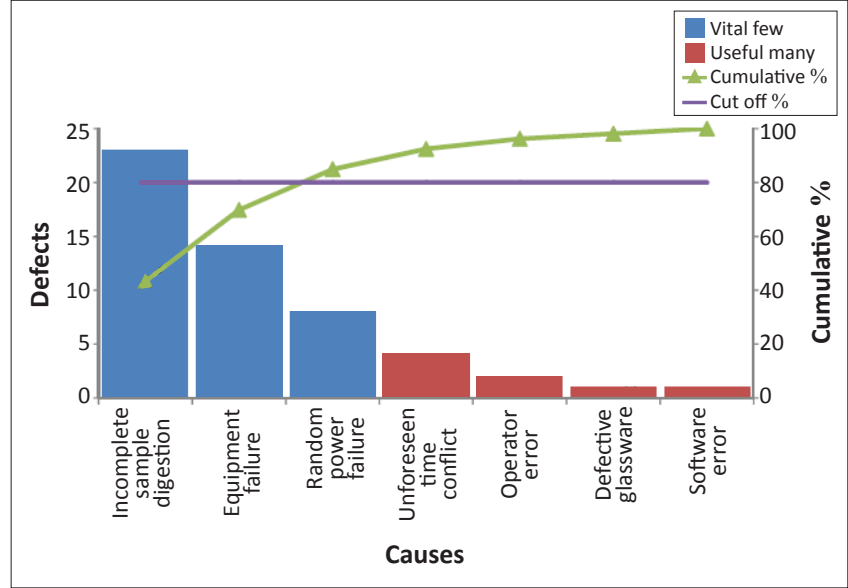

FIGURE 2: Pareto chart - Pareto analysis: Selenium analysis process.

TABLE 2: Table of assignable causes of quality problems in selenium analysis process.

\begin{tabular}{llll}
\hline $\begin{array}{l}\text { Cause } \\
\text { number }\end{array}$ & Assignable causes & $\begin{array}{l}\text { Number of } \\
\text { occurrences }\end{array}$ & $\begin{array}{l}\text { Cumulative percentage } \\
\text { cut-off: } 80 \%\end{array}$ \\
\hline 1 & Incomplete sample digestion & 23 & 43.4 \\
\hline 2 & Equipment failure & 14 & 69.8 \\
\hline 3 & Random power failure & 8 & 84.9 \\
4 & Unforeseen time conflict & 4 & 92.5 \\
\hline 5 & Operator error & 2 & 96.2 \\
6 & Defective glassware & 1 & 98.1 \\
7 & Software error & 1 & 100.0 \\
\hline
\end{tabular}

from data obtained from the process steps. The use of basic quality-tools enabled the analysis of the primary process data, or P-criteria.

Results obtained during the Measure phase, which primarily involved the analysis of the future state value stream map has been depicted (Figure 4). During this phase, additional 
R-criteria were collected for analysis by means of a controlled experiment.

The Analyse phase involved intensive statistical analysis of quantitative data, whereby the R-criteria obtained from the process were analysed. The results of Total Regression Analysis on Standard Calibration Curves (Table 5) and CRM Analysis (Table 6) yielded result measures known as R-criteria for further analysis.

Further analysis of this data included the determination of precision, bias and HorRat of the process, systematic error analysis, process capability analysis, ANOVA hypothesis testing, the analysis of control chart data, and led to the following analogies:

- in the current state selenium analysis process, result quality was variable

- in the current state process, accuracy and process precision could be improved

- the overall current state process performance was poor

- systematic error was present in the current state selenium analysis process

- the current state selenium analysis process was experiencing a disparate loss in selenium yield from process run to process run.
The statistical analysis of research data centred on the determination of the following: The calculation of the $t_{\text {stat' }}$ known as the calculated $t$ statistic, also known as $t_{\text {calc }}$. In

TABLE 3: Effects of problems in selenium analysis process.

\begin{tabular}{lll}
\hline Cause number & Assignable causes & Effect of process failure \\
\hline 1 & $\begin{array}{l}\text { Incomplete sample } \\
\text { digestion }\end{array}$ & $\begin{array}{l}\text { Process time varies from } 15 \mathrm{~h} \\
\text { to } 18 \mathrm{~h}\end{array}$ \\
\hline 2 & Equipment failure & $\begin{array}{l}\text { Process delayed. Severity } \\
\text { determines rework }\end{array}$ \\
3 & Random power failure & $\begin{array}{l}\text { Process delayed, rework } \\
4\end{array}$ \\
5 & Unforeseen time conflict & Process delayed, rework \\
6 & Operator error & Results invalidated, rework \\
7 & Defective glassware & Rework, only on samples affected \\
\hline
\end{tabular}

TABLE 4: Results of P-criteria analysis.

\begin{tabular}{lll}
\hline Process measure & Description & Finding \\
\hline EFF & EFF = VAT / CT & $37.5 \%$ \\
VAT & Total critical time required & $54 \mathrm{~h}$ \\
CT & Average process cycle time & $144 \mathrm{~h}$ \\
NVAT & NVAT = CT - VAT & $90 \mathrm{~h}$ \\
$\begin{array}{l}\text { Kaizen } \\
\text { opportunities }\end{array}$ & $\begin{array}{l}\text { Improvement } \\
\text { opportunities }\end{array}$ & $\begin{array}{l}\text { Sample waiting time, sample } \\
\text { digestion, sample preparation and } \\
\text { selenium detection }\end{array}$ \\
\hline
\end{tabular}

EFF, overall process efficiency; VAT, total value added time; $C T$, overall process cycle time NVAT, total non-value added time.

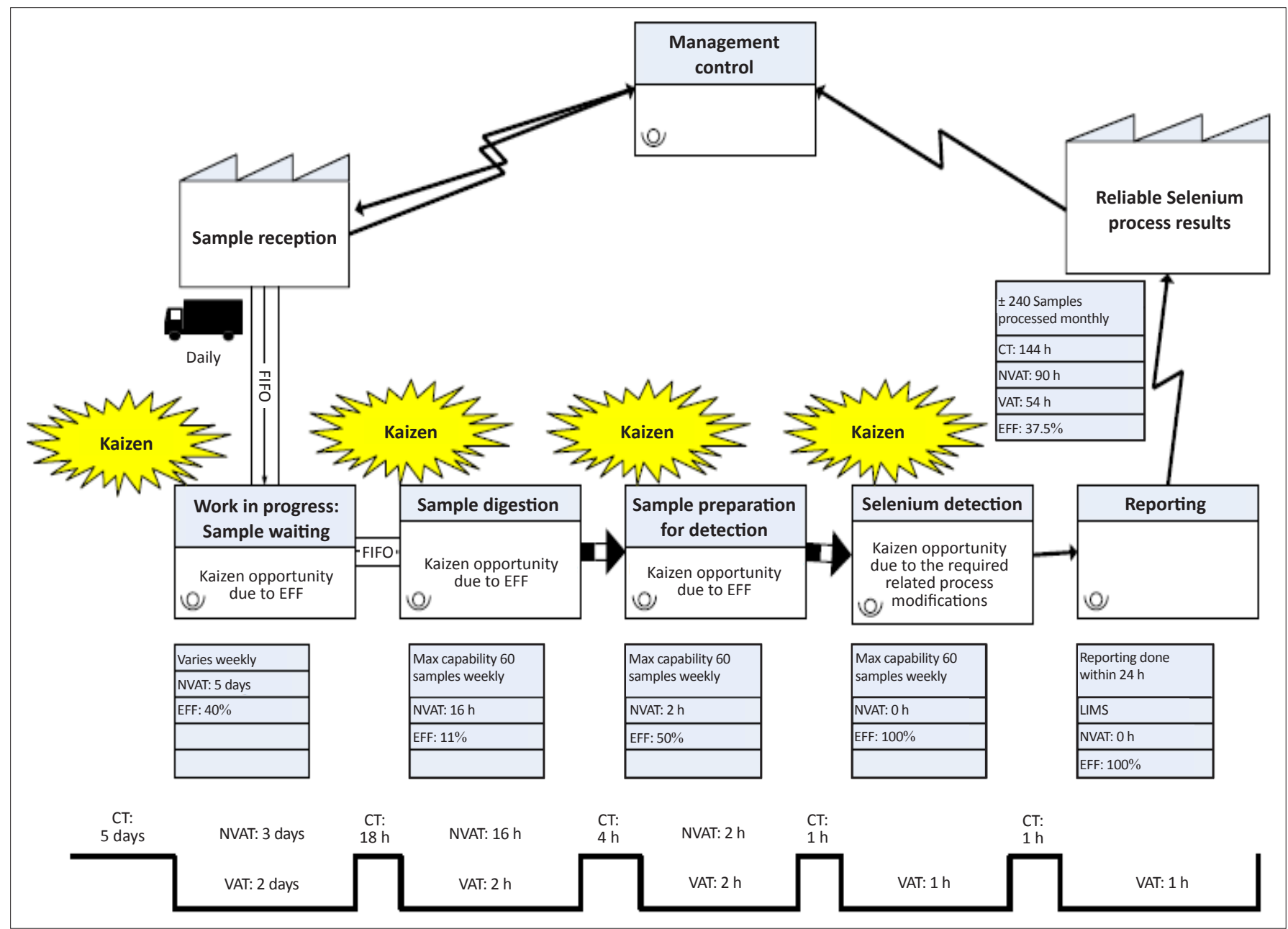

CT, cycle time; VAT, value added time; NVAT, non-value added time; EFF - VAT/CT, efficiency; FIFO, first in first out.

FIGURE 3: Current state value stream map. 
statistics, the $t$ distribution is used to estimate the population mean when or is unknown. The $t_{\text {crit' }}$ or critical value was obtained from the $t$-distribution table. The calculated $f$-statistic, or $f_{\text {calc, }}$ also known as $f_{\text {stat }}$ was calculated. In statistics, the $f$-distribution is used for testing the equality between the variances of populations. The $f_{\text {crit' }}$ or critical value was obtained from the $f$-distribution table. Analysis of Variation, a statistical methodology, was used to compare the means of groups. The regression SS, also known as Regression Sum of Squares (SSR), which is equal to the sum of the squared differences between the predicted value of $Y$ and the mean of $Y$ was determined, whereas the residual SS, also known as the Error Sum of Squares (SSE), which is equal to the sum of the squared differences between the observed value of $Y$ and predicted value of $Y$, was also determined. Significant linearity exists where SSR > SSE. Furthermore, the Regression MS was determined. The Regression MS is also known as Regression Mean Square $($ MSR $)=\frac{\text { SSR }}{\mathrm{k}}$, where SSR is Regression Sum of Squares or explained variation and residual MS, which is

Error Mean Square (MSE) $=\frac{\mathrm{SSR}}{n-\mathrm{k}-1}$

[Eqn 1]

where $\mathrm{k}=$ number of independent or explanatory variables in the regression model. Furthermore, the $S_{y / x}$ was calculated. The standard error of regression, also known as Standard Error of the Estimate, or Residual Standard Deviation or
Random Calibration Uncertainty, is a measure of the amount of error accrued in predicting a $y$-value for each given $x$-value. This statistic measures the variability of the actual $y$-values from the predicted $y$-values. It is a measure of variation around the fitted line of regression and is measured in units of the dependent variable $y$, and was determined.

The $\mathrm{S}_{\mathrm{b}^{\prime}}$ also known as Standard Error of Slope or $\mathrm{S}_{\mathrm{b} 1^{\prime}}$ is a statistic that determines the sensitivity of the calibration function or the rate at which the signal changes with concentration. The $\mathrm{S}_{\mathrm{a}^{\prime}}$ Standard Error of the Intercept or $\mathrm{S}_{\mathrm{a} 1^{\prime}}$ is the error associated with the actual intercept point of the line. The intercept of the regression line has implications for the smallest detectable signal (measured response) and the corresponding lowest concentration. These were also calculated during statistical analysis of the research data. Confidence Levels (CL), is the probability that the interval estimate will include the population parameter. $b$, also known as the corresponding confidence level for $b$ associated with $S_{b}$ (interval of the slope), was calculated by using the $t$-statistic for $(n-2)$ degrees of freedom. $t_{\mathrm{Sb}^{\prime}}$ calculated as the product of $t_{\text {crit }}$ and $\mathrm{S}_{\mathrm{b}}$, whilst $\mathrm{a}$, or the corresponding confidence level for $\mathrm{a}$, associated with $\mathrm{S}_{\mathrm{a}}(y$-intercept), was calculated in the same way as that of the slope. $t_{\mathrm{Sa}^{\prime}}$ calculated by using the $t_{\text {crit }}$ and $\mathrm{S}_{\mathrm{a}}$; the Limit Of Detection (LOD) were determined as $X_{\text {lod }}$ or the concentration representing LOD, and $Y_{\text {lod }}$ or the response representing the LOD. The Limit Of Quantitation (LOQ) was

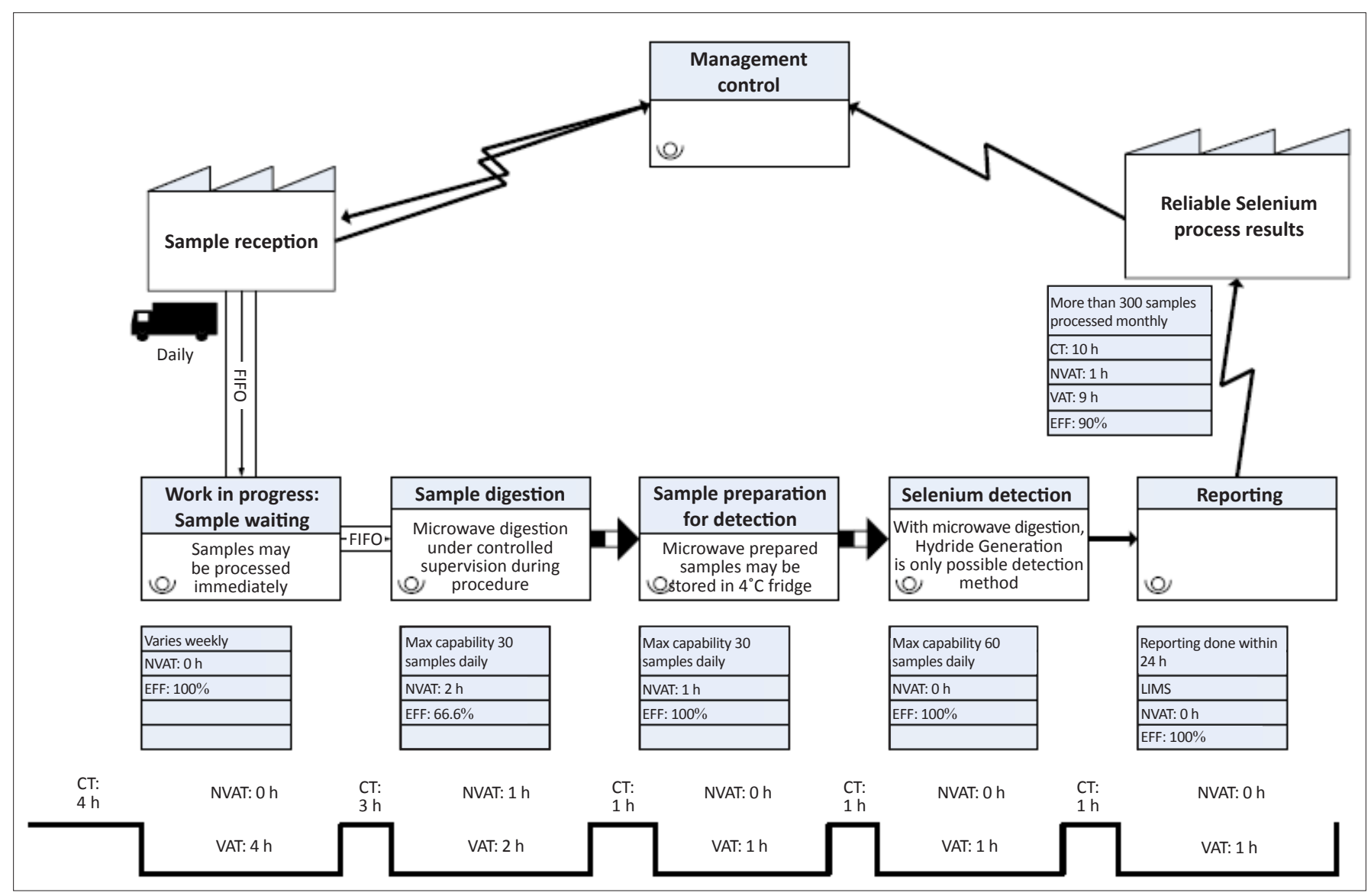

CT, cycle time; VAT, value added time; NVAT, non-value added time; EFF - VAT/CT, efficiency; FIFO, first in first out.

FIGURE 4: Future state value stream map. 
TABLE 5: Total Regression Analysis.

\begin{tabular}{|c|c|c|}
\hline Category of method characteristic & Description & Result \\
\hline \multirow[t]{4}{*}{ Calibration curve standard } & Number of standards & 5 \\
\hline & Number of replicates & 13 \\
\hline & Standard spread & $10 \mathrm{ppb}-500 \mathrm{ppb}$ \\
\hline & Matrix of blank & Nitric Acid, Perchloric Acid \\
\hline \multirow[t]{12}{*}{ Linearity of calibration curve } & Linearity Correlation: Correlation coefficient & 0.999978 \\
\hline & Linearity Correlation: Coefficient of determination & 0.999956 \\
\hline & Significant Linearity, $t_{\text {stat }}$ of slope & 260.5602 \\
\hline & Significant Linearity, $t_{\text {crit }}$ & 3.18 \\
\hline & Significant Linearity: $t_{\text {stat }}>t_{\text {crit }}$ & As a result of $t_{\text {stat }}>t_{\text {crit' }}$, significant linearity exists. \\
\hline & Significant Linearity: $f_{\text {calc }}$ ANOVA & 67891.59 \\
\hline & Significant Linearity: $f_{\text {crit }}$ & 5.416 \\
\hline & Significant Linearity: $f_{\text {stat }}>f_{\text {crit }}$ & Since $f_{\text {calc }}>f_{\text {crit }}$ significant linearity exists. \\
\hline & Significant Linearity: Regression SS > Residual SS & $\begin{array}{l}\text { Regression SS }=159473 \\
\text { Residual SS }=7.0468 \\
\text { Regression SS }>\text { Residual SS; therefore, significant linearity exists. }\end{array}$ \\
\hline & Significant Linearity: Regression MS > Residual MS & $\begin{array}{l}\text { Regression MS }=159473 \\
\text { Residual MS }=2.3489 \\
\text { Regression MS }>\text { Residual MS; therefore, significant linearity exists. }\end{array}$ \\
\hline & Significant Linearity: Comment on significance of linearity & $\begin{array}{l}\text { A strong linear positive relationship between } x \text { and } y \text { was found } \\
\text { during regression and correlation analysis. }\end{array}$ \\
\hline & Significant Linearity: \% Variation in detection of sample & $99.9956 \%$ \\
\hline \multirow[t]{3}{*}{ Regression parameters } & Slope & 5.6741 \\
\hline & Intercept & 0.362516 \\
\hline & Regression line equation & $Y=5.6741 X+0.3625$ \\
\hline \multirow[t]{9}{*}{ Calibration uncertainties } & $\begin{array}{l}\text { Standard error of the regression: significance of standard } \\
\text { error of regression }\end{array}$ & $\mathrm{S}_{y / x}=1.5326$ \\
\hline & $\begin{array}{l}\text { Significance of standard error of the regression: comment } \\
\text { on } f \text {-test result with CRM }\end{array}$ & $\begin{array}{l}f \text {-test conducted to determine whether systematic error = variance } \\
\text { of CRM. (Calculation annexure) } \\
f_{\text {calc }}>f_{\text {crit }} \text {, thus rejected null-hypothesis. } \\
\text { As a result residuals were dispersed more widely than can be } \\
\text { accounted for by random error. Systematic error is present in process. }\end{array}$ \\
\hline & Uncertainty of slope: $\mathrm{S}_{\mathrm{b}}$ & 0.0218 \\
\hline & Uncertainty of intercept: $\mathrm{S}_{\mathrm{a}}$ & 0.9776 \\
\hline & Ratios of slope and intercept uncertainties: $\mathrm{S}_{\mathrm{a}}$ and $\mathrm{S}_{\mathrm{b}}<\mathrm{S}_{y / x}$ & $\begin{array}{l}\mathrm{S}_{\mathrm{a}} \text { and } \mathrm{S}_{\mathrm{b}}=0.99939 \text {, thus } \mathrm{S}_{\mathrm{a}} \text { and } \mathrm{S}_{\mathrm{b}}<\mathrm{S}_{y / x} \text {. This is evidence of good } \\
\text { general precision. }\end{array}$ \\
\hline & Ratios of slope and intercept uncertainties: $\mathrm{S}_{\mathrm{a}} / \mathrm{S}_{\mathrm{b}}$ & $\begin{array}{l}\text { Ratio: } 44.89 \\
\text { More standards are needed at the lower end of the standard } \\
\text { calibration curve. }\end{array}$ \\
\hline & Ratios of slope and intercept uncertainties: $\mathrm{S}_{\mathrm{b}}<\mathrm{S}_{\mathrm{a}}$ & $\mathrm{S}_{\mathrm{b}}<\mathrm{S}_{\mathrm{a}}$ thus working range is sufficient \\
\hline & Confidence limits at $95 \%: 95 \% \mathrm{CL}$ of $\mathrm{b}: \mathrm{b} \pm t_{\mathrm{Sb}}$ & $5.6741 \pm 0.0693$ \\
\hline & Confidence limits at $95 \%: 95 \% \mathrm{CL}$ of a: $\mathrm{a} \pm t_{\mathrm{Sa}}$ & $0.3625 \pm 3.1088$ \\
\hline \multirow[t]{8}{*}{ LOD } & $\begin{array}{l}\text { LOD from regression statistics } \\
\text { (ISO } 11843 \text { method) } \\
X_{\text {lod }}=\frac{Y_{\text {lod }}-\mathrm{a}}{\mathrm{b}} \text { or } X_{\text {lod }}=\frac{\left(\mathrm{a}+3 \mathrm{~S}_{y / x}\right)}{\mathrm{b}}\end{array}$ & $\begin{array}{l}Y_{\text {lod }}=\mathrm{a}+3 \mathrm{~S}_{y / x} \\
Y_{\text {lod }}=0.3625+(3 \times 1.532624) \\
Y_{\text {lod }}=0.3625+(4.497872) \\
Y_{\text {lod }}=4.960388 \sim 4.96 \rightarrow \text { (lowest instrument response) }\end{array}$ \\
\hline & Concentration representing LOD from regression statistics & $X_{\mathrm{lod}}=\frac{Y_{\mathrm{lod}}-\mathrm{a}}{\mathrm{b}}$ \\
\hline & & $X_{\text {lod }}=\frac{\left(\mathrm{a}+3 \mathrm{~S}_{y / x}\right)-\mathrm{a}}{\mathrm{b}}$ \\
\hline & & $X_{\mathrm{lod}}=\frac{4.9603-0.3625}{5.6741}$ \\
\hline & & $X_{\mathrm{lod}}=\frac{4.5978}{5.6741}$ \\
\hline & & $X_{\text {lod }}=0.810313529 \sim 0.81 \rightarrow$ \\
\hline & & $\begin{array}{l}\text { Therefore this method could only detect selenium concentrations } \\
\text { larger than } 0.81 \mathrm{ppb} \text {. All selenium concentrations detected were far } \\
\text { above this value. }\end{array}$ \\
\hline & & $\begin{array}{l}\mathrm{X}_{\text {lod }}=0.81 \mathrm{ppb} \\
\text { (lowest concentration) }\end{array}$ \\
\hline LOQ & LOQ from regression statistics & $\begin{array}{l}Y_{\text {loq }}=\mathrm{a}+10 \mathrm{~S}_{y / x} \\
Y_{\text {lod }}=0.3625+(10 \times 1.532624) \\
Y_{\text {lod }}=0.3625+(15.32624) \\
Y_{\text {lod }}=15.68874 \sim 15.69 \rightarrow(\text { lowest response with reasonable reliability) }\end{array}$ \\
\hline
\end{tabular}

LOD, Limit of detection; LOQ, Limit of Quantitation; $t_{\text {stat }}$ calculated $t$-statistic; $t$ - critical value obtained from the $t$-distribution table; $f$, calculated $f$-statistic; ANOVA, Analysis of Variation $f_{\text {crit }}$ critical value obtained from the $f$-distribution table; $f_{\text {stat }}$, calculated $f$-statistic; Regression SS, Regression Sum of Squares (SSR); Residual SS, the Error Sum of Squares (SSE); Regression MS, Regression Mean Square (MSR); Residual MS, Error Mean Square (MSE); CRM, Certified Reference Material; $\mathrm{S}_{\mathrm{b}^{\prime}}$, standard error of slope or $\mathrm{S}_{\mathrm{bl}}$; $\mathrm{S}_{\mathrm{a}^{\prime}}$, standard error of the intercept; $\mathrm{S}_{\mathrm{v} / \mathrm{x}^{\prime}}$ standard error of regression; $t_{\mathrm{sb}}$, used during the calculation of confidence limits associated to the interval of the slope $\left(\mathrm{S}_{\mathrm{b}}\right)^{\prime}$, it is the product of the $t_{\text {crit }}$ and $\mathrm{S}_{\mathrm{b}}$, $t_{\mathrm{sa}}$, used during the confidence limits associated to the instrument response ( $\mathrm{S}$ ), it is the product of the $t_{\text {cit }}$ and S; ISO, International Organisation for Standardisation; CL, Confidence Levels; $X$, concentration representing LOD; $Y_{\text {ba, }}$, response representing the LOD; a, the corresponding confidence level for $\mathrm{a}$, associated with $\mathrm{S}_{\mathrm{a}} ; \mathrm{b}$, the corresponding confidence level for $\mathrm{b}$, associated with $\mathrm{S}_{\mathrm{b}} ; Y_{\text {log }}$, signal representing the LOQ; $X_{\text {log, }}$, signal representing the LOQ; 
TABLE 5 (Continues...): Total Regression Analysis.

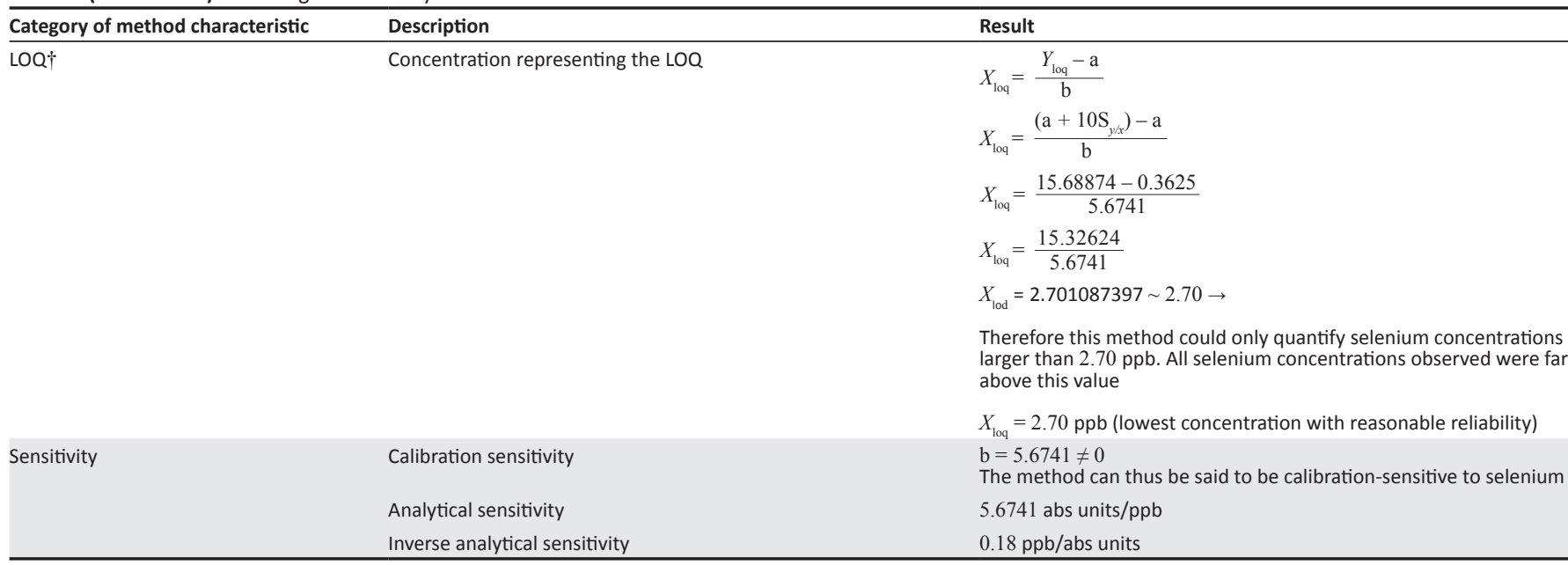

LOD, Limit of detection; LOQ, Limit of Quantitation; $t_{\text {stat' }}$ calculated $t$-statistic; $t_{\text {crit' }}$ critical value obtained from the $t$-distribution table; $f_{\text {calc }}$ calculated $f$-statistic; ANOVA, Analysis of Variation $f_{\text {crit' }}$ critical value obtained from the $f$-distribution table; $f_{\text {stat }}$ calculated $f$-statistic; Regression SS, Regression Sum of Squares (SSR); Residual SS, the Error Sum of Squares (SSE); Regression MS, Regression Mean Square (MSR); Residual MS, Error Mean Square (MSE); CRM, Certified Reference Material; $\mathrm{S}_{\mathrm{b}}$, standard error of slope or $\mathrm{S}_{\mathrm{b}}$; $\mathrm{S}_{\mathrm{a}}$, standard error of the intercept; $\mathrm{S}_{y / x^{\prime}}$ standard error of regression; $t_{\mathrm{Sb}}$, used during the calculation of confidence limits associated to the interval of the slope $\left(\mathrm{S}_{\mathrm{b}}\right)$, it is the product of the $t_{\text {crit }}$ and $\mathrm{S}_{\mathrm{b}} ; t_{\mathrm{Sa}}$, used during the confidence limits associated to the instrument response ( $\mathrm{S}$ ), it is the product of the $t_{\text {crit }}$ and $\mathrm{S}_{\mathrm{a}}$; ISO, International Organisation for Standardisation; CL, Confidence Levels; $X_{\mathrm{lod}}{ }^{\prime}$ concentration representing LOD; $Y_{\text {lod }}$, response representing the LOD; a, the corresponding confidence level for a, associated with $\mathrm{S}_{\mathrm{a}} ; \mathrm{b}$, the corresponding confidence level for $\mathrm{b}$, associated with $\mathrm{S}_{\mathrm{b}} ; Y_{\text {loq }}$, signal representing the LOQ; $; X_{\text {loq' }}$, signal representing the LOQ.

$\dagger$, Data continues from previous page.

TABLE 6: Certified Reference Material Analysis.

\begin{tabular}{ll}
\hline Mean measurement & $\mathbf{0 . 5 2 3 5}$ ppm \\
\hline $\begin{array}{l}\text { Evidence from reputable CRM that } \\
\text { method is selective and/or specific } \\
\text { for selenium. }\end{array}$ & $\begin{array}{l}\text { NCS ZC 71001: Beef liver Certified } \\
\text { Reference Material. NCS ZC 71001 is } \\
\text { certified at 0.56 } \pm 0.07 \text { ( } \mu \mathrm{g} / \mathrm{g} \text { ) or ppm. } \\
\text { Current state selenium method is } \\
\text { selective and specific for selenium in } \\
\text { CRM. }\end{array}$ \\
$\begin{array}{ll}t \text {-test to determine significant } \\
\text { difference between the mean and }\end{array}$ & $\begin{array}{l}t_{\text {calc }} \text { is less than } t \text { crit; thus null-hypothesis } \\
\text { is accepted which states that the results } \\
\text { obtained from the analytical process is } \\
\text { not significantly statistically different to } \\
\text { the true CRM-value. }\end{array}$ \\
$\begin{array}{ll}05 \% \text { CL and Cl } & 0.52 \pm 0.09 \text { (True value: } 0.56 \pm 0.07 \text { ) }\end{array}$ \\
Precision & $16.02 \%$ \\
Bias & $-6.5 \%$ \\
Horwitz function & $1.82 \%$ \\
\hline
\end{tabular}

CRM, Certified Reference Material, controls or standard sample material used to check the quality and traceability in analytical chemistry; CL, Confidence Levels, the probability that the interval estimate will include the population parameter; $\mathrm{Cl}$, Confidence Interval, a range of values used to estimate a population parameter and associated with a specific confidence level; $t_{\text {calc }}$ also known as $t_{\text {stat }}$ (calculated $t$-statistic); $t_{\text {crit' }}$ Critical value obtained from the $t$-distribution table.

calculated where $Y_{\text {loq }^{\prime}}$ known as the signal representing the LOQ, was calculated.

The Improve phase involved the Kaizen analysis of P-criteria, in addition to further R-criteria analysis of data obtained from the improved analytical method process (Table 7).

Analogies drawn from the analysis of P-criteria, which highlighted the root causes of quality problems and identified the improvement opportunities, were:

- sample digestion was the root cause of problems associated with the process of selenium analysis

- a value stream of activities was identifiable in the current state process

- muda were identified as a form of process waste to be removed through modification

- muri was identified as a form of process waste to be removed through modification
- mura was identified as a form of process waste to be removed through modification

- heijunka (process improvement) was possible in the form of process modification

- the design of process control features assures the quality output of the modified process design.

Analysis that took place in the Control phase of Lean Six Sigma entailed FMEA, a quality-tool, whereby P-criteria, or information on potential failure points of the improved process, were analysed (Table 8 ).

In summary the key research findings were that the selenium analysis process at WCPVL was problematic in terms of delivering quality of results. The open heat-block sample digestion procedure was identified as the major root cause of quality problems; however, a modification to the digestion procedure could not be accomplished successfully without a modification in selenium detection, from fluorometric detection to hydride generation detection. The current state selenium analysis process operated at $37.5 \%$ process efficiency; however, a value stream was identifiable in the process. Optimisation of the value stream to a modified process resulted in $90 \%$ potential efficiency.

The current state selenium analysis process was found to be reasonably accurate and reasonably precise, but a definite systematic error is present in the process. Systematic error is a known cause of poor accuracy and precision. Unstandardised process steps resulted in a systematic error in the process. This process performance is unacceptable and the process requires heavy control and inspection. With a process capability index of 1.02 the process is, however, potentially capable.

Process variation was out of statistical control, and data analysis found evidence of disparate loss in selenium yield, 
TABLE 7: Kaizen approach to improvement to selenium analysis process.

\begin{tabular}{|c|c|c|c|c|}
\hline Problem area & Lean focus & Problem & Description of problem & Lean solution \\
\hline $\begin{array}{l}\text { Sample waiting time } \\
\text { Sample digestion, Sample preparation }\end{array}$ & Mura & Volatile incoming work & $\begin{array}{l}\text { Laboratory capacity to process } \\
\text { inherently volatile incoming } \\
\text { workload. Process cannot be } \\
\text { streamlined }\end{array}$ & Microwave digestion \\
\hline $\begin{array}{l}\text { Sample waiting time } \\
\text { Sample digestion, Sample preparation }\end{array}$ & Muri & Too much WIP & $\begin{array}{l}\text { WIP results in non-value added } \\
\text { effort to control, track and } \\
\text { prioritise samples and rework. }\end{array}$ & Microwave digestion \\
\hline Sample waiting time & Muda & Long and unnecessary lead times & $\begin{array}{l}\text { Individual samples queue until } \\
\text { similar samples arrive to } \\
\text { constitute an efficient test run }\end{array}$ & Microwave digestion \\
\hline Sample digestion, Sample preparation & Muri & Variable lead time & $\begin{array}{l}\text { Overnight digestion time varied } \\
\text { from week to week with } \\
\text { open-heat-block digestion }\end{array}$ & Microwave digestion \\
\hline Sample detection & Heijunka & $\begin{array}{l}\text { Accurate, precise and reliable } \\
\text { results }\end{array}$ & Microwave digestion & Hydride generator detection \\
\hline
\end{tabular}

WIP, work-in-progress.

TABLE 8: Failure modes and effects analysis recommendations.

\begin{tabular}{|c|c|}
\hline Failure mode & Action step recommended \\
\hline Sample registration failure & $\begin{array}{l}\text { Internal Lab: selenium analysis sample } \\
\text { control worksheet }\end{array}$ \\
\hline \multirow[t]{2}{*}{ Digestion failure } & $\begin{array}{l}\text { Failure Type 1: ensure maintenance } \\
\text { schedule is upheld }\end{array}$ \\
\hline & $\begin{array}{l}\text { Failure Type 2: previous selenium method } \\
\text { as backup }\end{array}$ \\
\hline Reduction phase failure & $\begin{array}{l}\text { Ensure back-up apparatus is available: } \\
\text { water bath and thermometer }\end{array}$ \\
\hline $\begin{array}{l}\text { Incorrect measurement } \\
\text { parameters (detection } \\
\text { instrument) }\end{array}$ & $\begin{array}{l}\text { Ensure adequate training is provided } \\
\text { to technicians. Training records and } \\
\text { competency certificates serve as } \\
\text { evidence }\end{array}$ \\
\hline \multirow[t]{2}{*}{ AAS failure } & $\begin{array}{l}\text { Failure Type 1: ensure maintenance } \\
\text { schedule is upheld }\end{array}$ \\
\hline & $\begin{array}{l}\text { Failure Type 2: ensure spare part } \\
\text { selenium lamp is in stock }\end{array}$ \\
\hline \multirow[t]{2}{*}{ HG failure } & $\begin{array}{l}\text { Failure Type 1: ensure maintenance } \\
\text { schedule is upheld }\end{array}$ \\
\hline & $\begin{array}{l}\text { Failure Type 2: ensure spare part piping } \\
\text { is in stock }\end{array}$ \\
\hline Reporting: electronic system & None: wait until system is online \\
\hline
\end{tabular}

AAS, Atomic Absorption Spectrophotometer; HG, Hydride Generation.

as process results varied quantitatively from weekly process runs. Process redesign offered a remedy in the form of a modified selenium process, assumed to produce superior results in terms of accuracy and precision. Modified process design enabled control features to be built into the design.

\section{Trustworthiness}

\section{Reliability of analytical data}

In order to ensure reliability of analytical data during the research process, scientific measurements are not reported as single values, but rather as ranges or averages with estimates of error surrounding a value after repeated measurements of the value. The statistical standard deviation of the range of measurements obtained from 13 repeated trial runs was tabulated and used to compute a confidence interval around research results. Confidence intervals provide an estimate of the probability that a similar result will be found if the study is repeated.

\section{Validity of analytical data}

According to Capri and Egger (2003) 'uncertainty is inherent in scientific research'. An important requirement of scientific research is, therefore, to identify and quantify uncertainty and to assess the reliability of scientific data. Research data obtained and used for the purpose of this study were consequently statistically analysed, and uncertainty was determined according to a technique known a Total Regression Analysis as proposed by Fraser (2011).

Data error was categorised as random error or systematic error. Random error is derived from unpredictable variation, and therefore cannot be controlled. Reducing uncertainty in the system, however, helps to correct systematic error as well as to minimise random error. Increasing the amount of observations of a measurement is considered to be one avenue of reducing uncertainty, although uncertainty may never be reduced to zero (Carpi \& Egger 2003). As a consequence of error, scientific measurements were not reported as single values, but rather as ranges, or averages with estimates of the error surrounding the value, after repeated measurement of the value. All analytical data for the research conducted were reported with confidence levels to account for error, as well as the associated confidence limits, to reflect the precision of statistical estimates computed during research.

Furthermore, the inclusion of CRM analysis conducted as part of the research process also supports the validity of research data results.

\section{Discussion Outline of the results}

As a means to prove or disprove the research hypothesis, which reads, 'variation in process, time and control procedures have a direct impact on the disparity in selenium testing results', the study focussed on the stated research objectives. In alignment with the primary research objective, which was set 'to establish an alternative more accurate and safer digestion procedure within the selenium analysis process in order to attain quality improvement of the process'; suitable quality-tools were selected and used in a very precise manner to realise this objective. This practical demonstration of the successful use of quality-tools in a Lean Six Sigma framework, in a clinical chemistry research environment, enabled process improvement through the identification of significant quality risks to the process being studied. The outcome of this approach was a modified SOP, which inserts 
functional practical benefit to the operational system in the biochemistry laboratory.

A secondary objective 'to determine if a modification of the existing hot plate digestion to microwave digestion is capable of reducing the risks associated with the digestion procedure', was stated. The result of the process capability studies during Lean Six Sigma highlighted that the elimination of quality risks, such as process variation, results in an improved analytical process. The literature review (Desert Research Institute 2004; University of Alberta, Department of Environmental Health and Safety 2011) highlighted that the use of perchloric acid is hazardous to the process operator and to the environment. As a result, a modification of the selenium analysis method away from the use of perchloric acid may be regarded empirically as a form of process improvement. Furthermore, the use of the FMEA quality-tool culminated in further functional practical value to the Biochemistry operational system by ensuring that risks associated with the modified selenium analysis method, were minimal.

Key research findings which focussed on the secondary objective stated as 'determining if a modification of the existing digestion method will result in the optimisation of selenium yield of the process', was generated from result data, which served as evidence of the disparate loss of selenium yield during the current state selenium analysis process. This selenium loss was attributed to process variation, and a standardised modification of the selenium analysis process overcomes this quality problem. Foster (2007) contends that the Improve, or Kaizen, phase of Lean Six Sigma involves off-line experimentation, whereby the factors affecting process performance are analysed. Kurkova et al. (2008) stated that, at temperatures exceeding $70{ }^{\circ} \mathrm{C}$, organic forms of selenium volatilise from samples. Optimisation of the process to microwave digestion and HG-AAS detection was therefore regarded as a quality improvement of the process.

The final research objective stated, namely 'to determine whether a modification of existing digestion procedure will ultimately translate into an improvement in terms of reliability of results', had clear tangent planes to the independent variable of the research hypothesis, that is, quality improvement and laboratory results. Key findings, based on the analysis of research data, were that both accuracy and precision of the current state selenium process would be improved by a modified selenium analysis process. Both process capability studies and process performance studies conducted supported this finding, which further emphasised the importance of this practical improvement to biochemistry laboratory processes. Reliability of an analytical method is the ability of the method to be both accurate and precise. Therefore, an improvement in both accuracy and precision with the modified selenium analysis process, would ultimately improve the reliability of the analytical process, and thereby the quality of the process.

\section{Practical implications}

The significant benefit gained from this research, has been the practical value secured by the improvement of an analytical biochemistry process in a very demanding diagnostic environment. An improvement in terms of process efficiency and reliability renders valuable resources available for other activities required in the section, such as laboratory technologist time, and equipment resources. Furthermore, by reducing cycle time, results can be produced by the section in a reduced time period, ensuring reliability of diagnoses.

\section{Limitations of the study}

Results from this research were reflective of normal operating conditions of WCPVL and is not a reflection of process or system operation during emergency situations that may occur, such as an outbreak of a controlled disease.

\section{Recommendations}

The following recommendations were made as a result of this research study:

- the current state selenium analysis process must be modified in order to assure the reliability of process results

- process modification is necessary to address process variability that resulted from process steps, time and control procedures in the process, which were found to be responsible for disparate results

- process modification from open heat-block to microwave digestion is recommended

- process modification from fluorometric selenium detection to hydride generation detection is recommended

- it is recommended that the modified process be monitored, and that continuous evaluation take place according to the Lean Six Sigma cycle to maintain a focus on continuous improvement of the selenium analysis process.

\section{Conclusion}

Measurable benefit can be attained from research that has been adequately constructed and designed, with a clear and consistent focus on the desired research objectives. Conclusions were drawn from key research findings in response to each of the research objectives. Process standardisation in terms of time and stricter temperature control in a closed digestion system is regarded as capable of overcoming process variation. From this statement, it follows that a modified process design, focussed on both sample digestion and detection, is capable of overcoming unacceptable systematic error process variation and provide the process with better control features. Furthermore, a modified selenium analysis process, which includes a modified sample digestion procedure, will result in the reduction of biohazard and other risks associated with the selenium analysis process, and the assumption is made that a modification from open heat-block digestion will optimise the selenium yield of the analytical laboratory process. 
In addition, a modified process design would ultimately translate into an improvement in quality in terms of the reliability of process results. On the basis of conclusions drawn from key research findings, it can be stated with confidence that:

there is significant evidence to accept the stated null-hypothesis, and it was found that variability of the dependant variable of the research hypothesis, associated with the process, had a significant and detrimental impact on the independent variable of the research hypothesis, namely, the result quality of the selenium analysis process. (Cloete 2011, n.p.)

As a result, the research hypothesis was accepted as true.

\section{Acknowledgements}

The research was funded by the Department of Agriculture of the Western Cape. Tremendous thanks are extended to the management and staff at WCPVL for their support and assistance during the research process. The authors would like to thank both Prof. Dr J. André Watkins and Mr André Bester for their mentorship and supervision.

\section{Competing interests}

The authors declare that there are no competing interests that may have inappropriately influenced the presentation of information in this paper.

\section{Authors' contributions}

B.C.C. (Western Cape Provincial Veterinary Laboratory) is a M. Tech (Quality) student at the Cape Peninsula University of Technology and conducted the research. A.B. (Cape Peninsula University of Technology) was the supervisor of this research project.

\section{References}

Allen, T., 2006, Introduction to engineering statistics and Six Sigma: Statistical quality control and design of experiments and systems, Springer-Verlag, London.

American Association for Clinical Chemistry, 2011, How reliable is laboratory testing? viewed 03 July 2011, from http://labtestsonline.org/understanding/features/ reliability/?start $=0$

American Society for Quality, 2011, Lean Kaizen: A simplified approach to process improvement, viewed 07 October 2011, from http://asq.org/training/lean-kaizena-simplified-approach-to-process-improvement KAIZEN.html

Anvari, A., Ismail, Y. \& Hojjati, S., 2011, 'A study on total quality management and Lean manufacturing: Through Lean thinking approach', World Applied Sciences Journal 12(9), 1585-1596.

Berte, L., 2007, CD-ROM, 'Laboratory quality management: A roadmap', Clinical Chemistry and Laboratory Medicine 27, 771-790.

Blumberg, B., Cooper, D. \& Schindler, P., 2011, Business research methods, third European edition, McGraw-Hill Education, Berkshire.
Byrne, G., Lubowe, D. \& Blitz, A., 2008, Driving operational innovation using Lean Six Sigma, viewed 27 September 2011, from http://www-935.ibm.com/services/at/ bcs/pdf/br-stragchan-driving-inno.pdf

Cawley, J., 2000, Process capability analysis in laboratory quality control, viewed 10 March 2011, from http://www.nwasoft.com/press/mag_sci0110

Carpi, A. \& Egger, A., 2003, The scientific method, viewed 26 June 2011, from http:// www.visionlearning.com/library/module_viewer.php?mid=45

Cloete, B., 2011, 'An approach to the improvement of the selenium analysis process of the Western Cape Provincial Veterinary Laboratory', M. Tech thesis, Dept. Industrial and Systems Engineering, Cape Peninsula University of Technology.

Dahlgaard, J., Kristensen, K. \& Gopal, K., 2002, Fundamentals of total quality management: Process analysis and improvement, Taylor \& Francis, London.

Desert Research Institute, 2004, Guidelines for using and storing perchloric acid, viewed 10 October 2011, from http://www.safety.dri.edu/.../PerchloricAcidGuidelines. pdf

Ducros, V., Ruffieux, D., Belin, N. \& Favier, A., 1994, 'Comparison of two digestion methods for the determination of selenium in biological samples', Analyst 119 1715-1717. http://dx.doi.org/10.1039/an9941901715, PMid:7978324

Foster, S., 2007, Managing quality: Integrating the supply chain, Pearson Prentice Hall, New Jersey.

FMEA Information Centre, 2011, Failure modes effects analysis, viewed 05 October 2011, from http://fmeainfocentre.com/index.htm

Fraser, A., 2011, Email, 08 September, allan@allanfraserandassociates.co.za

Gryna, F., Chua, R. \& DeFeo, J., 2007, Juran's quality planning and analysis: For enterprise quality, McGraw-Hill, Singapore.

Hare, L., 2001, Chicken soup for processes: Understanding variation as a prerequisite for SPC, viewed 10 July 2011, from http://asq.org/pub/qualityprogress/ past/0801/qp0801stats.pdf

Hubbard, B., 2010, Muda, Mura and Muri, viewed on 11 October 2011, from http:// bobsleanlearning.wordpress.com/2010/01/14/muda

Jiang, W., Murphy, T. \& Tsui, K., 2006, 'Statistical methods for quality and productivity improvement', in H. Pham (ed.), The Springer Handbook of Engineering Statistics, pp. 173-174, Springer, New Jersey.

Khalil, M., Khan, M. \& Mahmood, T., 2006, 'Lean Six Sigma - A tool to improve productivity, quality and efficiency in manufacturing and industrial sector',
paper presented at the Official Conference of the International Association for Management Technology, P. R. China, Beijing, 22-26 May.

Kurkova, T., Skrypnik, L. \& Zalieckiene, E., 2008, 'Features of plant material pretreatment for selenium determination by atomic absorption and fluorimetric methods', Chemija 19(1), 40-43.

Marquis, P., 2011, Email, 21 July, phil@multiqc.com

Moen, R. \& Norman, C., 2011, Evolution of the PDCA cycle, viewed 02 July 2011, from pkpinc.com/files/NA01MoenNormanFullpaper.pdf

Nevalainen, D., 1999, CD-ROM, 'The quality systems approach', Archives of Pathology \& Laboratory Medicine, 123.

Park, S. \& Anthony, J., 2008, Robust design for quality engineering and Six Sigma, World Scientific Publishing Co. Pte. Ltd., Singapore. http://dx.doi.org/10.1142/6655

Process Management International Ltd., 2009, Green Belt Workshop: Part 1, Published in-house, Meriden

SANS 17025, 2005, General requirements for competence of testing and calibration laboratories, Standards South Africa, Pretoria.

Scott, J., 2007, CD-ROM, 'Process optimization for service organisations isn't rocket science', Quality Progress, 5.

Tarin, P., 2006, 'Distribution, speciation and geochemistry of selenium contaminated marine sediments - Port Kembla Harbour, NSW, Australia', PhD thesis, School of Earth and Environmental Sciences, University of Wollongong.

University of Alberta, Department of Environmental Health and Safety, 2011, CCIS 2 Fume Hood Standard Operating Procedure, Published in-house, Canada.

Van Leeuwen, J., Nauta, M., De Kaste, D., Odekerken-Rombouts, Y., Oldenhof, M. Vredenbregt, M. et al., 2009, 'Risk analysis by FMEA as an element of analytical validation', Journal of Pharmaceutical and Biomedical Analysis 50(5), 1085-1087. http://dx.doi.org/10.1016/j.jpba.2009.06.049, PMid:19640668

Wang, J., 2008, 'Quality process improvement', in S. Gad (ed.), Pharmaceutical Manufacturing Handbook, Regulations and Quality, n.p., John Wiley \& Sons Inc. New Jersey.

Woodall, W., 2000, 'Controversies and contradictions in statistical process control', Journal of Quality Technology 32(4), 341-350.

Wu, C., Pearn, W. \& Kotz, S., 2009, 'An overview on theory and practice on process capability indices for quality assurance', International journal of production economics 117(2009), 338-359. 